\title{
A RAG system for the management forensic and archaeological searches of burial grounds
}

\author{
Alastair Ruffell ${ }^{1}$, Sean McAllister ${ }^{2}$ \\ ${ }^{1}$ School of Geography, Archaeology \& Palaeoecology, Queen's University, Belfast, N. Ireland, UK, BT7 1NN \\ ${ }^{2}$ DiscoverEverAfter/SFM Engineering, 15A Main Street, Portglenone, County Antrim, N. Ireland, UK, BT44 8AA
}

Email address:

a.ruffell@qub.ac.uk (A. Ruffell)

\section{To cite this article:}

Alastair Ruffell, Sean McAllister. A RAG System for the Management Forensic and Archaeological Searches of Burial Grounds. International Journal of Archaeology. Special Issue: Archaeological Sciences. Vol. 3, No. 1-1, 2015, pp. 1-8. doi: 10.11648/j.ija.s.2015030101.11

\begin{abstract}
Burial grounds are commonly surveyed and searched by both police/humanitarian search teams and archaeologists. One aspect of an efficient search is to establish areas free of recent internments to allow the concentration of assets in suspect terrain. While $100 \%$ surety in locating remains can never be achieved, the deployment of a red, amber green (RAG) system for assessment has proven invaluable to our surveys. The RAG system is based on a desktop study (including burial ground records), visual inspection (mounding, collapses) and use of geophysics (in this case, ground penetrating radar or GPR) for a multi-proxy assessment that provides search authorities an assessment of the state of inhumations and a level of legal backup for decisions they make on excavation or not ('exit strategy'). The system is flexible and will be built upon as research continues.
\end{abstract}

Keywords: Burial Grounds, Clandestine Graves, RAG System, Ground-Penetrating Radar, Search

\section{Introduction: Why the Need to Assess Burial Grounds}

Three main reasons exist to answer the above question. First, burial grounds can be used for the burial of murder victims and other items associated with criminal activity (1). Secondly, historically, unbaptized, diseased, homosexual and insane persons were also buried in or near graveyards and cemeteries $(1,2)$, after which archaeologists are sometimes asked to locate and exhume. Thirdly, expanding urban and peri-urban populations in many areas of the world where burial of the dead is common (as opposed to cremation) is resulting in pressure on space for future burials (2): assessment of such ground is often also undertaken by archaeologists. The third scenario replicates over a longer time period (but in far higher global numbers), the problems of past epidemics, where large numbers of inhumations were required (3). The search of cemeteries and graveyards is a sensitive topic, making managing the search particularly important. Consideration of how to search burial grounds is already underway by teams throughout the world, with the United Kingdom as but one example: see (4). The main conflict however is between those who own or manage the land (usually state and church) and thus manage burials, and relatives of victims or the public, who wish to know what is buried where. As early as 1843, John Loudon was designing graveyards both for their aesthetic qualities, as well as more practical issues of space (5). The global problem is exemplified by cities with rapid growth and poor land management (6), where unregulated burials can occur. Many solutions are proposed, from better management (lawn cemeteries) of regular locations (7), to vertical cemeteries or mass mausolea, as is already used in some high water table and crowded island contexts (e.g. throughout the Mediterranean, New Orleans, to name but two), offshore cemeteries and areas with strict regulations on cremation and re-use. Whilst modern burial grounds are well-managed, in the past, the problem of an expanding population translated into increased numbers of the dead needing burial. Where management was good, quite often this was on paper records that have not all stood the test of time and cannot be relied on for assessment of what is buried where. We have developed a simple system that may assist in the management of searches of graveyards, in itself a complex and sensitive subject. This system works well for most of the mixed peat-clay-sand 
based soils in a temperate climate of Ireland, where we have developed it. Other studies have applied similar techniques elsewhere (see references below), suggesting the system may have wider applicability, possibly using different assets to those we use: this requires the specific testing of such techniques in different environments. What we wish to stress here is not the specific methods or ground conditions (important though they are to the specific locations), but the overall concept of a conjunctive strategy, using available and appropriate methods, to the search of burial grounds.

\section{Commonly-Used Methods in the Location of Burials}

Most of the methods used by those charged with assessing the location of burials are self-evident and require little explanation. These frequently begin with a visual inspection of grave markers such as headstones, together with information from the site caretaker(s), their records and testimony from relatives. In the past, a metal probe (8) was often used to assess the presence of a coffin, although no gravedigger we spoke to would go on record as admitting this. Mounded or subsident areas of earth are likewise apparent, (although see below, where these may provide falsepositives). More sophisticated methods of burial detection (such as geophysics) have largely been restricted to locating the graves of famous people (see the work of Field et al [8] who searched for Percy Rutherford's grave and Ellwood et al., [9], who searched for the grave of Texan gunslinger William Longley) or of testing methods for the detection of buried victims of homicide $(10 ; 11 ; 12,13 ; 14,15,1)$. The need to establish the possible presence of human remains and focus a search, or conversely free space that need not be a priority for searching, has resulted in the present work being partly reliant on geophysics, but with moderation as no easy body/coffin locating mechanism or device has been devised. By far the most popular geophysical method used for the detection of graves, is ground penetrating radar or GPR (see references above). Space precludes a full description of the method; the above references on graveyard and homicide searches sufficing to provide the interested reader with the necessary background: there are numerous other papers on the use of geophysics to detect graves: this is not the central subject of this paper. Some essential aspects of the GPR method include the following. Antenna frequency is chosen in regard to target size and depth: small objects only being resolved on higher frequency (e.g. 1GHz) antennas, but maybe only to 1 metre depth; a lower frequency will allow greater depth penetration (tens of metres), but may not image an object of say $50 \mathrm{~cm}$ or $1 \mathrm{~m}$ diameter. The method of detection relies on buried or hidden materials possessing a different chemistry to its surroundings, resulting in a change in dielectric permittivity between target and host. The method thus has the capability to image an organic object in nonorganic host medium, such as a body in sand. Radar waves of a certain frequency are introduced into a medium, and any change (as above) may cause a reflection to the wave. These reflected returns are analysed and stacked together to produce a cross-section of the time taken for the radar wave to enter and reflect through the medium: such cross sections are termed radargrams. In addition, multiple radargrams can be placed alongside each other and the signal viewed horizontally, as a map or time slice of the subsurface. GPR suffers poor data returns in wet clay ground and total loss of signal in salt water, but works exceptionally well in sand, ice, freshwater, peat, concrete and rock. Much more needs to be known about GPR operation, data processing and interpretation before a non-specialist conducts a survey: the above papers will provide something of a starting point, with references therein.

\section{The RAG System}

The red, amber, green system of colour coding maps has a long and complex history, as summarized by Donnelly \& Harrison (16). This complexity is partly due to the origin of the RAG being within military circles, most likely the British Army in the First World War. Similarly confusing is the fact that for movement of tanks, soft ground would be red or a no-go area, when for burying objects; this would be a go or suitable area. Donnelly \& Harrison (16) adhere to this classification in their maps of a likely homicide grave in northern England, where red is shown as soft, or diggable, or most likely to contain an inhumation. To create a RAG map, certain information is desirable, as is the case for burial sites, all be it that much of the information is probably known (subjectively) by the cemetery or graveyard manager. Nonetheless, our recommendation is to include such witness testimony within the desktop study, rather than rely wholly upon it, or ignore it. Some of the essential criteria for a desktop study, prior to burial site survey and RAG assessment, are provided below.

1. Geology: A geological evaluation will be made, based on published solid and drift maps, ground outcrop, soil maps and topographic surveys.

2. Records of Past Land Use: These are primarily survey maps, of the area and the graveyard/cemetery, but anecdotal sources (as above) may be included here.

3. Hydrological - Hydrogeological Mapping: Pre-existing groundwater vulnerability maps are of use, along with combined geology and geomorphology (above) that will allow definition of small-scale (tens of metres) watersheds, catchments, confluences, springs and sinks. These will comprise the likely flow-paths entering or emanating from the graveyards. Geochemical surveys of waters near the burial site may have been undertaken, or be evident from other data, such as sites close to sea level may have a saline water table, precluding the use of some geophysical methods of grave detection.

4. Geophysics. Previous surveys may have been made of the area. Geological surveys, archaeology societies may know of the existence of such data.

5. GIS. The above data is best stored and viewed in a 
Geographic Information System such as ARC QGIS or GRASS such that data can be statistically and independently compared, and stored for a long period of time (with the increasing use of data clouds, theoretically data can exist forever (in human terms).

While the authors are advocates of the full desktop study, as this brings forth information that would have caused problems for the survey, in the case of graveyards, the amount of human activity, brought in material, multiple digging/inhumations complicate the issue so much, some realistic limits to the desktop must be set. The authors own experience is that a desktop is essential, but should not be used as an excuse for not attempting to deploy the search assets suggested here, as they often work when the desktop suggests they should not, and visa versa. The desktop study for burial grounds is best used to supply a level of assurance: sand- peat- based soils indicate that results should be good: wet clay would make the GPR operator hesitant to promise results. In countries with good transport links, then a trial survey can be incorporated into the desktop study. Where the survey location cannot be checked prior to fieldwork, so the desktop study is important, but a decision on the level of risk concerning possible poor results must be made for financial reasons. On completion of a desktop study, our preferred method is to combine three elements into the RAG system we propose. First, is there a grave marker (headstone, other placed feature, location on a graveyard map)? Second is there a physical feature present (collapse or mound)? Third, is a clear geophysical anomaly present? In this case GPR is used, but other authors $(10 ; 11 ; 14,15)$ have shown resistivity and electromagnetics as possible. No feature indicates Green, or diggable in the old (military) usage of the RAG system, but excellent for us as it means 'clear to be used'; two of the three features indicates Amber (sometimes amber crosshatching for reproduction in black and white). All three features denote Red, or probability of an inhumation present (we use a red colour outline to the area, such that we can annotate inside the plot). Green situations are not described from burial grounds below, as they usually comprise an area of flat grass, other vegetation, rough ground of made ground.

\section{Examples}

\subsection{Headstone but no Body-Amber Code}

This is a common scenario in many burial grounds and is most typically, but not exclusively, a product of time and conditions degrading the corpse and any enclosing medium. Older graves (typically more than 1-200 years), or graves in acid soils, with resilient (more often than not stone) markers tending not to have a significant geophysical anomaly.

Figure 1 shows an early 1700s burial ground in Co. Down, Northern Ireland that was surveyed using both GPR and electromagnetic methods (with no anomalies present at any of the eight possible plots indicated by the headstones) and excavated by archaeologists (with no coffin/casket or bones recovered). Exceptions occur of course, where subsurface anaerobic conditions occur, both bones and soft tissue can be preserved for longer periods of time. Subsurface movement (coffin slip/cadaver slip: see Roksandic, 2007) is also common in this scenario, most likely on sloping ground, but also on flat ground where a subsurface dip in soils, drift or geology occurs. Such movement of the cadaver may lead to designation of an Amber Code. This instance can cause some unexpected lack of discoveries, with coffins and/or cadavers moving in the subsurface with little surface expression. Disinterment (legally or illegally) can also cause remains to be absent, although when legal, grave markers such as headstones are usually moved as well. Although settling and subsidence are most common in the years following a burial (depending on coffin type and soil makeup), mounded earth can exist at a grave for significant period of time.

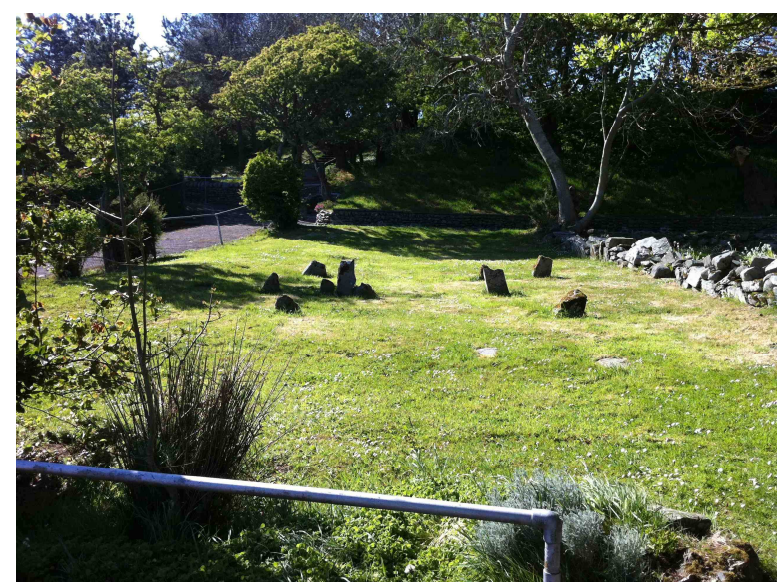

Figure 1. The 1700's period burial site described in text, with obvious headstones, but no geophysical anomaly or excavated remains present. An Amber classification until excavation was complete.

Figure 2 shows just such a case, although the age of the burials in this churchyard in Co. Leitrim (Republic of Ireland) are not known: given the age of the protestant church and social dynamic of the population, they are likely to date from the early to mid $1800 \mathrm{~s}$. All of these mounds were associated with a clear GPR anomaly, presented below.

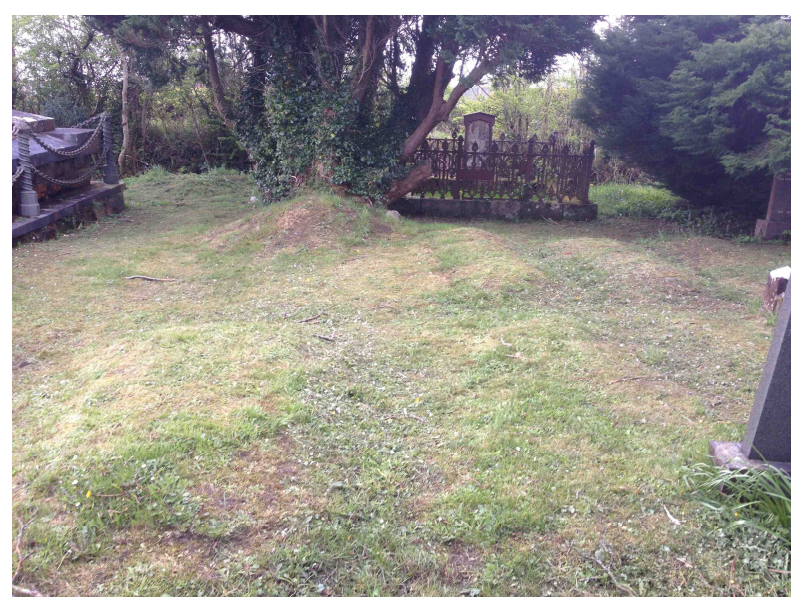

Figure 2. The mid 1800's graveyard described in text, with clear mounding on a scale consistent with burials, good geophysical anomalies (GPR, shown in other figures), but no headstones. An Amber classification. 


\subsection{GPR Anomaly but no Body - Amber Code}

During a police search of the area around a cemetery for possible buried homicide victims (in this case, two boys aged 9 and 11), collapsed ground in the shape and size of one or possibly two inhumations were observed. GPR surveys at two frequencies $(250$ and $500 \mathrm{MHz})$ confirmed that the collapsed ground extended to at least $1.5 \mathrm{~m}$ depth (Figures $3 \mathrm{a}$ and $3 b$ ), indicating this was not some minor product of soil movement or minor digging. A 3D GPR survey was instigated; that at 1 to $1.5 \mathrm{~m}$ showed two $\mathrm{E}-\mathrm{W}$ oriented elongate anomalies of around $1 \mathrm{~m}$ length (Figure $3 \mathrm{c}$ ). A police excavation showed these to be pits filled with waste from the demolition of an adjacent school: the anomalies were real enough but were not inhumations.

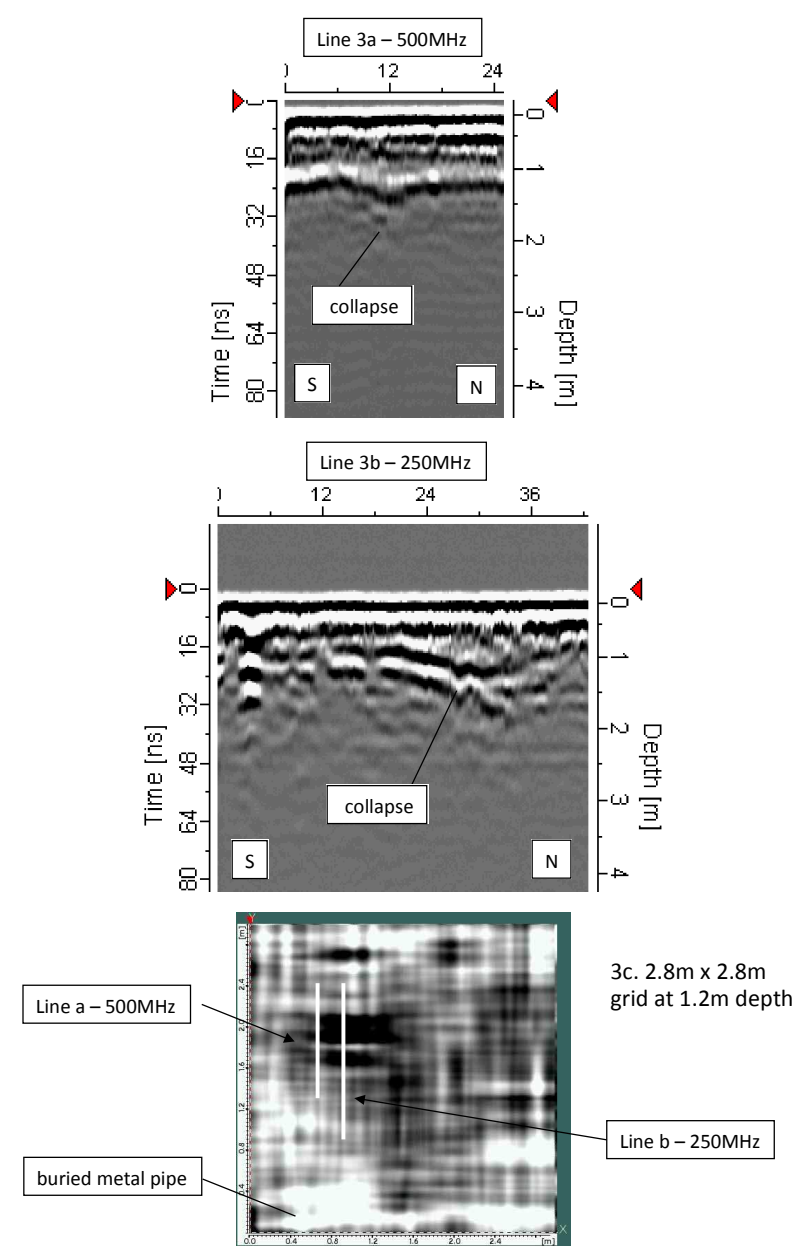

Figure 3. The no-body GPR anomalies (E-W black areas with $N-S 2 D$ profiles across the 'torso' areas) described in text, which were correct in context (on the edge of a cemetery, with intelligence to say bodies were interred here), with surface features, but no bodies: trenches filled with demolition waste were found by a police body recovery team.

\subsection{No GPR Anomaly but a Body - Incorrect Green Code}

Reliance on any geophysical method (GPR included) for indications of burials (above) is as problematic as excluding the possibility of an inhumation solely on this information is dangerous. A recent search of a location comprising beach sand showed no geophysical anomalies, yet local intelligence was definite that a body had been clandestinely placed in the area surveyed between 1971 and 1973. An excavation was undertaken and the skeleton of the deceased recovered. The post-survey review of the work ('exit strategy') included a desktop study of the location. This showed the beach sand in the area to comprise $50-70 \%$ shells, calcareous algae and limestone fragments: the skeletonized remains of the deceased showed no chemical (in this case, dielectric constant) contrast with the enclosing material, and thus no GPR anomaly.

\subsection{GPR Anomaly and Ground Disturbance (No Headstones or Grave Markers) - Amber and Red Codes}

This scenario is commonly found in historic burial locations where the local population could not afford stone markers, and in recent areas where epidemics or genocide have caused the digging and filling of graves with no markers archaeologists frequently encounter such locations. Grave markers may also degrade (especially wood, or poor-quality stone), or be removed for political reasons. In Ireland, the mass famine ('Potato Famine') of the mid 1800s caused just such a situation.

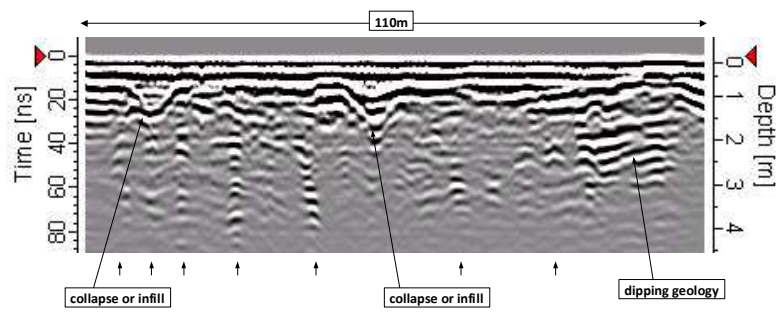

Figure 4. An example of a long GPR line that crosses at least seven (arrowed) unmarked burials, but with geometrically-correct subsident patches (Amber code, although bodies are very likely present here, as nearby excavations by archaeologists recovered three bodies in water-filled coffins). Data originally part of that shown in (17), adapted for this study. Note the collapsed ground: it is not known how these areas relate to the burials.

Figure 4 shows a long GPR profile through just such a location (described in more detail in [17]), and the complex subsurface ground conditions that can occur. Here, the burials are associated with a 'ringing' in the data (a set of vertical bands called multiples, below the inhumation) that are characteristic of some burials. Each of these were associated with depressions in the ground above, which together with the past maps of the area denoting this as 'burial ground' gave a high level of assurance (amber on the RAG system) that a burial existed at each location. Subsequent excavation of three of these locations confirmed the presence of roughly-made coffins, filled with water and with skeletonized remains inside. This discovery sounds like a success, however, further human bones were discovered outside of any ground depression or GPR anomaly, usually with no coffin and in mass graves. These had previously caused collapsed ground, which had been filled-in, being of larger volume than the individual graves. A further example of this type of burial is described below. Figures 5 and 6 are from our standard work in assessing working graveyards as part of a management strategy. 

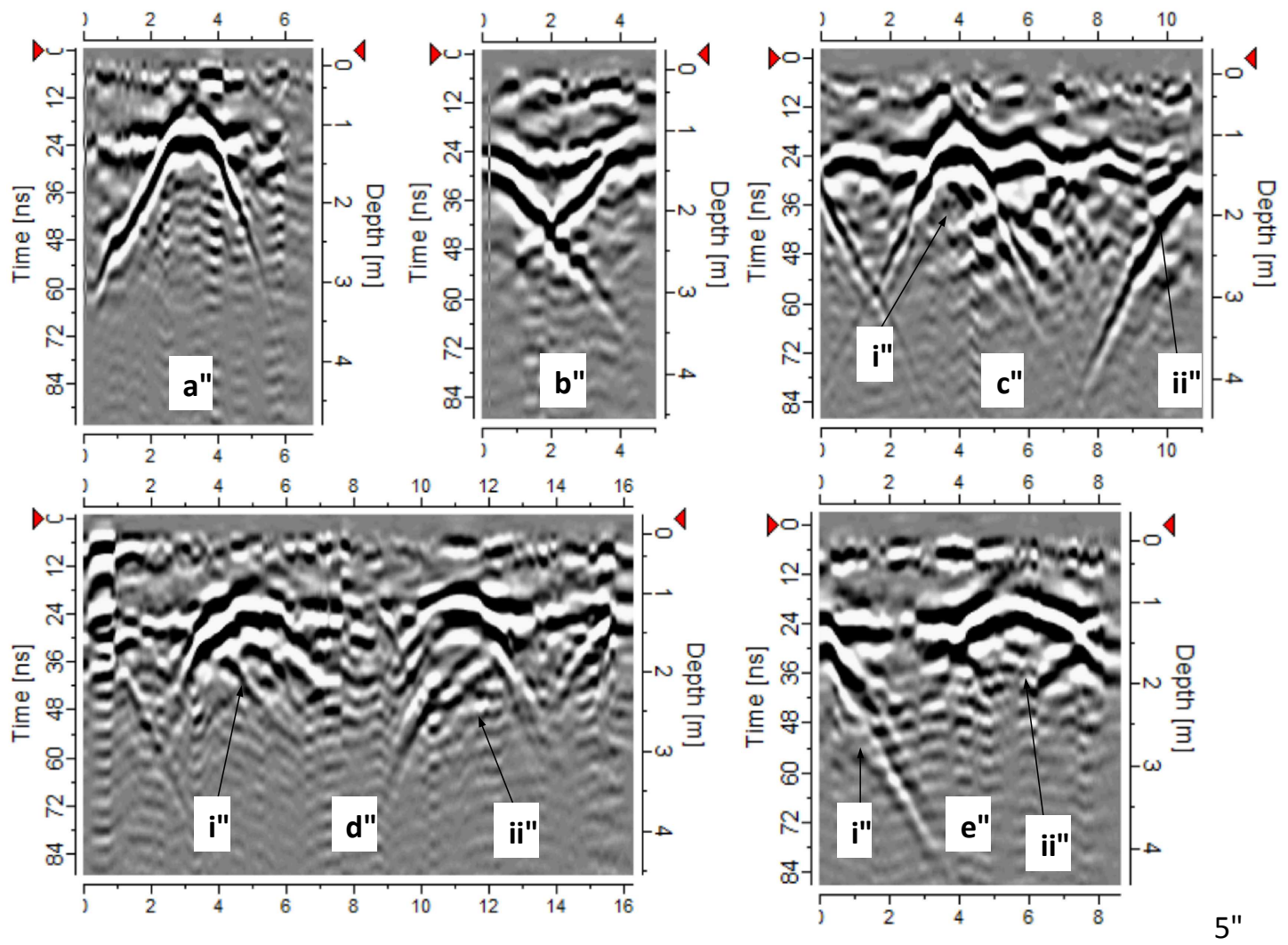

Figure 5. Classic GPR anomalies associated with inhumations of various types (single coffins, collapsed burials, double burials [side by side], multiple inhumations) described fully in text.
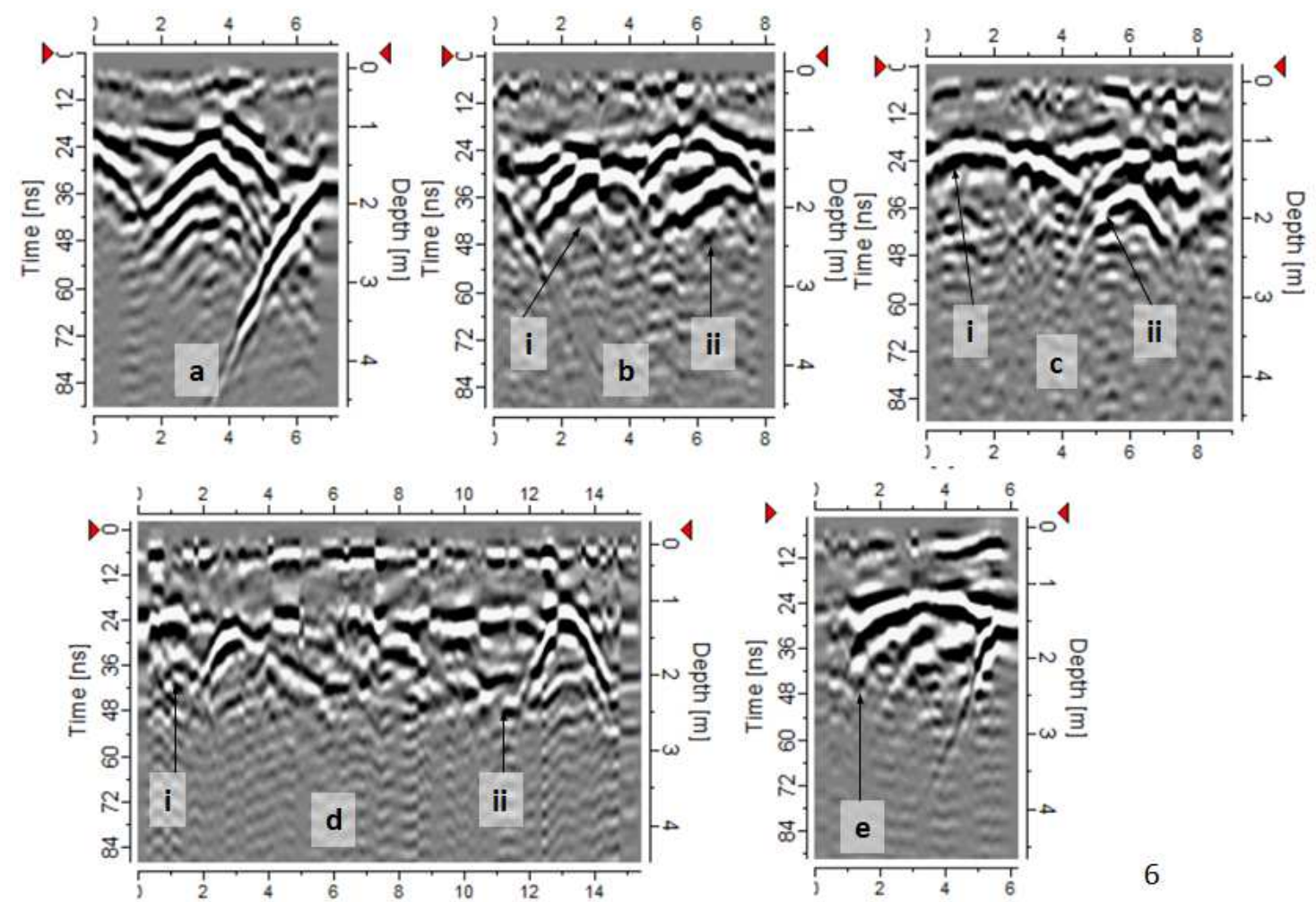

Figure 6. As in Figure 5: typical GPR anomalies associated with inhumations of various types (single coffins, collapsed burials, double burials [side by side], multiple inhumations) described fully in text. 
Figure 5a shows the most commonly sought-after GPR image, with the top of this unmarked burial at just less than a metre (the local water table is at about this level), with a hyperbolic shape to the sides, the classic 'ringing' effect seen in the unmarked burials (Figure 4), and a clear layer, possibly the water table on a sub-soil layer, at $1 \mathrm{~m}$ depth. Figure $5 \mathrm{~b}$ shows the opposite, and exemplifies the need for an experienced geophysical data interpreter to be employed. Here, the unmarked burial has collapsed, probably through combined loss of space in the cadaver chest area itself, but mostly through soil infilling the coffin. This destroys the geophysical response to the air- or fluid-filled coffin and thus the hyperbola that is commonly looked-for. Nonetheless, this location also had a coincident ground collapse (not surprisingly, but this at least showed the GPR data was not imaging some geological feature) and a wooden cross grave marker, and was thus also classed as Amber. Figure 5ci shows the classic hyperbola (as in Figure 5a), but here with a crested apex, but also the issue of a high-density of burials to the graveyard, as the signal ('swipe') from adjacent burials (one is denoted as ii) can be seen encroaching on the survey area. Family plots often contain multiple burials, and most common is to find family members of roughly the same age (most commonly, husband and wife) side-by-side with separate grave markers. In the best case, this is reflected by two grave outlines (depressions, mounds, plot boundaries) and discrete geophysical anomalies (as in Figure 5d, marked as $\mathrm{i}$ and ii). Often however, one broad anomaly is observed unless a higher-frequency radar antenna is used: the result is the same regardless; the site is denoted as Red on the RAG map, having a marker, a ground feature and a GPR anomaly. The simple hyperbola (Fig 5a) can sometimes be more complex (Figure 6a): in this case we know from church records that this plot has been re-used at least three times, although we would not expect such a regular set of ringing, or multiple hyperbolae through the grave site just as a result of this - more likely would be a complex internal structure. The pattern observed on Figure $6 a$, whilst excellent as a grave indicator (and thus with other intelligence, a Red classification), this pattern should not be taken as a key for multiple grave uses. It may well reflect episodes of infill (such as the burial ground managers filling in subsidence), not numerous inhumations per se. The image on Figure $6 \mathrm{~b}$ is a success, where three inhumations are imaged, a single burial to the left (i) and two, one placed above the other (above ii). We know this from the headstone record, and naturally a Red designation is made for the plot. Burials are made at different depths, even though legislation in many countries requires a minimum depth for different ground conditions. Shallower burials may be made where the water table is encroached upon, or where the sides of the grave start collapsing, or where there is risk of an adjacent burial slipping or collapsing into the opened site. All of these are the possible reasons for the images seen on Figure $6 \mathrm{c}$, where a shallow burial (possibly two, as the broad hyperbola may be a function of this inhumation for some reason) is next to, and from the geometry, later than the deep burial shown underneath. The grave plot itself can sometimes cause problems of interpretation: Figure 6d shows two clear burials (i and ii). However, a stone-outline plot with a recent (2003) burial occurs in the middle of the image (above d), where two vertical lines of dislocation in the data can be seen (where the antenna was dragged over the plot sides), but no characteristic hyperbola or collapse. The reasons for this are not known, but show the need for further research and why we stated at the start of this work that our RAG system is a working model. This middle location would be an Amber classification on the grounds extolled here, yet really should be a Red notation on common sense grounds: we often stick to the RAG system in these instances, and make a digitallylinked note to the effect that we have slightly varying views to the RAG (a note of caution basically) in this particular case. Figure $6 \mathrm{e}$ is included for completeness sake, it being a double use grave, the older hyperbola above the letter e and the younger one (confirmed by headstone dates), above: interference from an adjacent burial is seen (as above) to the right of the image.

\section{Mass Graves, Mausolea and Non- Listed Burials}

As mentioned above, unfortunately, mass graves are all too common, historically and more recently. A reader thinking that this is a topic for humanitarian ventures only would be mistaken as even currently-used burial grounds often have in or near them large burial sites. These maybe the result of epidemics (Spanish Flu, 1918; plagues of the 16th, 17th and 18th centuries (typhus, smallpox, cholera); war and genocide. A churchyard in the south of Belfast (N.Ireland) was used by us as a test ground for individual burials, it being close to the University and with supportive management. Maps of the ground showed an area denoted as 'poor ground' where a survey revealed no individual inhumations (such as in the other studies described here). Five pits, of a few metres across and 1.5 metres deep (see Figure 7) were resolved using GPR. These only have two attributes common to them (general location of graves and GPR anomalies), denoting them as Amber, but nonetheless useful for the planner, manager or surveyor to know about. Upstanding features such as mausolea should present few of the problems encountered with inhumations, it being obvious that a grave site exists, and if it's use or state of current occupants be in doubt, can be entered for visual inspection. Should entry be more difficult than a survey (unstable structure, locked or blocked access, family sensitivities), then geophysics (x-ray radiation, ultra-sonic, side-looking GPR: Figure 8) can all be used. However, few tests have been made of how such techniques perform against the reality of what lies inside, with further research necessary. Non-listed burials in graveyards are still common, from the clandestine placing of victims of drug abuse, venereal disease, accidental death and homicide in unmarked graves. The phenomena of unbaptized, prostitutes, homosexuals, the insane, being buried just 
outside a graveyard (less commonly a cemetery) occurs amongst those of certain religious faiths.

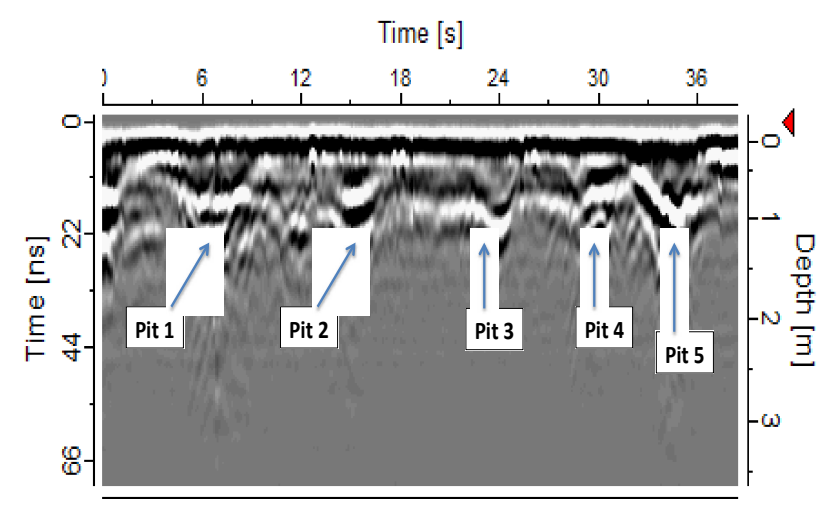

Figure 7. A GPR line from a mass grave (Irish Potato Famine, probably around 1852), with discrete pits as opposed to the collapses or hyperbola associated with individual burials.

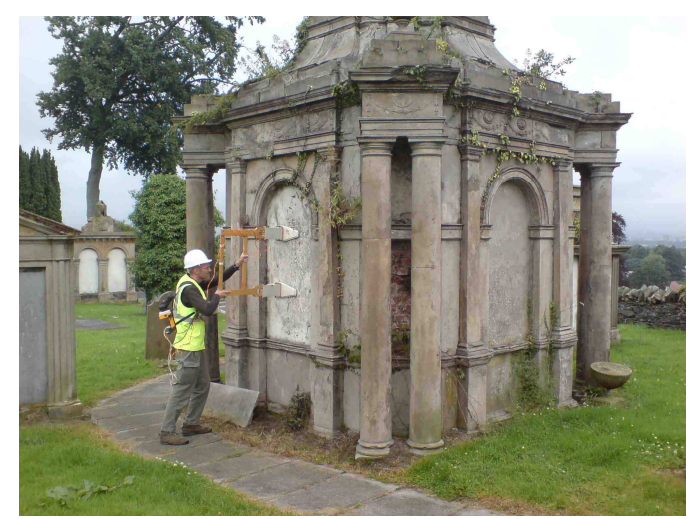

Figure 8. Use of the 400MHz unshielded GPR antennae on a mausoleum, for the detection of internal features.

\section{Summary - Deployment of the RAG System}

Having shown examples of our key criteria (headstones, Figure 1; mounds or depressions, Figure 2) and GPR features associated (rightly or wrongly) with burials (Figures 3, 4, 5, 6), we can demonstrate the use of these three in making a RAG map. Red in the traditional map means soft, or diggable and thus a likely burial location, and is useful here as the old 'no-go' notation for the military is the same for us, but the opposite for (16) as a Red code (diggable, likely substantial burial) is a 'go' for them, as they are looking for the buried murder victim, unlike us, who are avoiding the legally-buried deceased. In the field we deploy the above criteria, referenced to a laser sight or dGPS, so that we are absolutely sure each location is assessed, and never duplicated, as each digital station has a unique number. Where no feature is present, we survey at a $10 \mathrm{~cm}$ step size and $50 \mathrm{~cm}$ line spacing to cover every part of the area to be surveyed as Green. Assessment of a record (headstone, marker, site record), visual feature (depression, mound, change in vegetation) and geophysical indication is made, with none of the above, making the location Green (Figure 9).

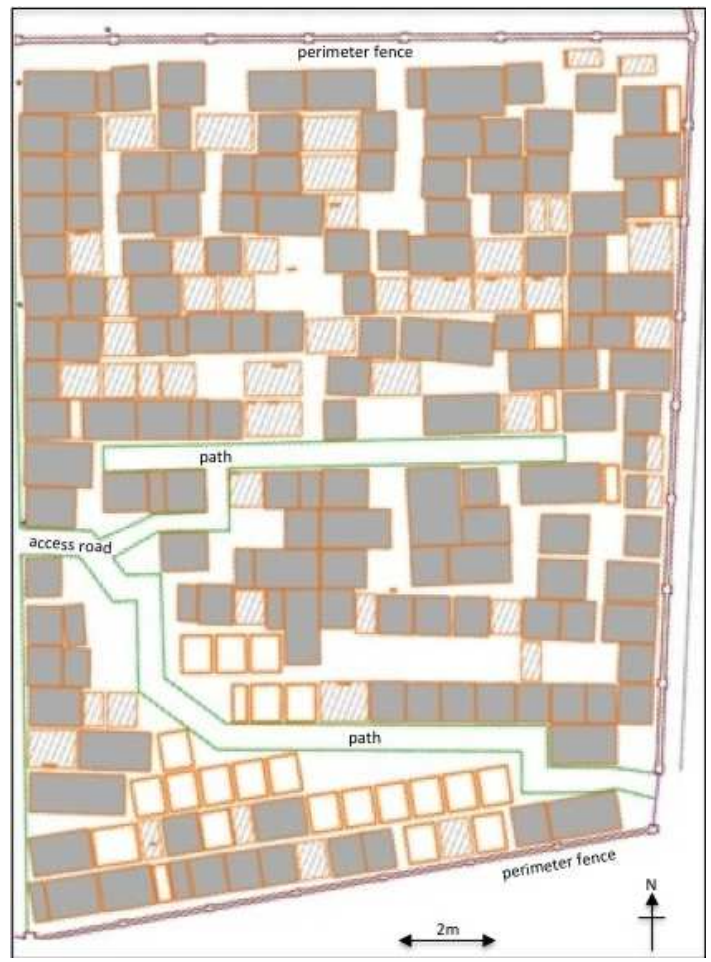

Figure 9. An example of a working RAG map (here an historic graveyard), based on the criteria described here, with Red (outlines) showing likely burials, Amber cross-hatching, possible burials (only proceed with caution) and light Green shading, no criteria for a burial present.

One or two of the above elevate the location to Amber (can proceed with caution, or avoid until all Green locations are used or searched). All three features signify Red, a burial is likely. What state it is in, we cannot tell, but at least the RAG gives a starting point for those carrying out the search. The ambiguity is in the Amber classification - which is intentional to allow our subjective view of the location to be given a description, as well as to reflect the above statement on the Red code, we cannot tell from the RAG system the exact nature of the burial, nor can we make a judgment as to how acceptable it is to re-us a plot, given our lack of knowledge as to what is present. At least with the Red notation, and some Green and Amber, the search coordinators and archaeological surveyors have a priority of sites to investigate further. The real issue is the persistence of human remains vs. the environment (mainly soil type and climate): Edmond Locard said 'every contact leaves a trace', suggesting that something will remain, in perpetuity. This is of course unrealistic, the Earth is a massive recycling machine and the 'trace' will eventually vanish. However, the authors have also heard police search teams, on finding nothing, mention 'returned to Earth', or indeed, the complete removal by micro and macro-organisms of all flesh and skeletal parts. Of course reality is between the two, depending on burial style (adult/child; wrapped/clothed/naked; chemicals added; soil type; climate). Some remains may be present for centuries following burial; that is not the point of this article, which is to prioritise locations for the search of recent and clandestine areas, 
which the RAG system can assist with. Perhaps with further research, such ambiguities can be further resolved and the RAG made more precise. Chemical 'sniffer' type devices, usually attached to a probe or using the spectral qualities of grave gas emissions, have been proposed (18) but suffer the same inaccuracy as GPR. The presence of decaying human remains may be significant enough to cause a gas anomaly, yet on exhumation may comprise only trace visual remains.

\section{Acknowledgements}

We are indebted to Finbar McCormick, Eileen Murphy, Colm Donelly and Brian Sloan (Queen's, Belfast), as well as John Hunter (Manlove Forensics) for general advice. Our surveys could not have been completed without the assistance of Father Alwill (Drumkeeran Church), Alan McCabe (Scadin Ltd), Gary Arbuthnot and Nigel Johnson (Police Service of N.Ireland), Geoff Knupfer (Independent Commission for the Location of Victim's Remains), Belfast Parks \& Gardens (access to Friar's Bush Graveyard).

\section{References}

[1] Ruffell A 2005, Searching for the IRA "disappeared": Ground penetrating radar investigation of a churchyard burial site. Journal of Forensic Sciences 50 1430-1435.

[2] Dunk J Rugg, J 1994, The Management of Old Cemetery land: Now and Future: a Report of the University of York Cemetery Research Group. Shaw \& Sons Ltd, London. 105p.

[3] Harding V 1993, Burial of the plague dead in early modern London. In: Epidemic and Disease in London, Champion JAI (ed) Centre for Metropolitan History Working Papers, 1, pp.53-64.

[4] Hart A Casper S 2004, Potential Groundwater Pollutants from Cemeteries. Environment Agency report. Environment Agency Publication, Almondsbury, Bristol. 35pp.

[5] Loudon J Claudius 1843, On the Laying Out, Planting and Managing of Cemeteries. Longman, Brown, Green and Longmans. 151pp.

[6] O'Neill KL 2012, There is no more room: cemeteries, personhood and bare death. Ethnography 13 510-530.

[7] Rugg J 2000, Defining the place of burial: what makes a cemetery a cemetery? Mortality: Promoting the interdisciplinary study of death and dying 5 259-275.
[8] Field G Leonard G Nobes D C 2001, Where is Percy Rutherford's grave? In: Jones, Martin \& Sheppard, Peter (Eds.) Australasian Connections and New Directions: Proceedings of the 7th Australasian Archoometry Conference, Research in Anthropology and Linguistics University of Auckland 5 123140.

[9] Ellwood BB Owsley DW Ellwood SH Mercado-Allinger PA 1994, Search for the grave of the hanged Texas gunfighter, William Preston Longley. Historical Archaeology 28 94-112.

[10] Buck SC 2003, Searching for graves using geophysical technology: field tests with ground penetrating radar, magnetometry and electrical resistivity. Journal of Forensic Sciences 48 5-11.

[11] France D L Griffin T J Swanburg JG Lindemann JW Davenport GC Trammell V Travis CT Kondratieff B Nelson A Castellano K Hopkins D Adair T 1997, Necrosearch revisited: further multidisciplinary approaches to the detection of clandestine graves. In: Haglund, W.D., Sorg, M.H. (Eds.), Forensic Taphonomy: the Postmortem Fate of Human Remains. CRC Press, pp. 497-509.

[12] Nobes D C 1999, Geophysical Surveys of Burial Sites: A Case Study of the Oaro Urupa. Geophysics 64 357-367.

[13] Nobes D C 2000, The search for "Yvonne": A case example of the delineation of a grave using near-surface geophysical methods. Journal of Forensic Sciences 45 715-721.

[14] Pringle JK Jervis J Cassella JP Cassidy NJ 2008, Time-lapse geophysical investigations over a simulated urban clandestine grave. Journal of Forensic Sciences 53 1405-1417.

[15] Pringle JK Jervis JR 2010, Electrical resistivity survey to search for a recent clandestine burial of a homicide victim, UK. Forensic Science International 202 e1-e7.

[16] Donnelly LJ Harrison M 2013 Geomorphological and geoforensic interpretation of maps, aerial imagery, conditions of diggability and the colour-coded RAG prioritization system in searches for criminal burials. In: Pirrie D Ruffell A Dawson L (Eds) Environmental and Criminal Geoforensics. Geological Society, London, Special Publications 384 173-194.

[17] Ruffell A McCabe A Donnelly CJ Sloan B 2009, Location and assessment of an historic (15-60 years old) mass grave using geographic and ground-penetrating radar investigation, NW Ireland. Journal of Forensic Sciences, 54, 15-26.

[18] Ruffell A 2002, Remote detection and identification of organic remains. Archaeological Prospection 9 115-122. 